\title{
Where Identity and Trauma Converge: Hindu-Muslim Perceptions of the 2002 Gujarati Riots
}

\author{
Nishant G. Patel, Psy.D. and Sanjay R. Nath, Ph.D. \\ Widener University
}

\begin{abstract}
The 2002 Gujarati Riots were one of the worst outbreaks of violence between Hindus and Muslims in India in recent history. There has been a lack of studies that have looked at victims' experiences of the riots and their processing of trauma sequelae related to the riots. Ten Gujarati Hindus and seven Gujarati Muslims were interviewed who were in Gujarat during the 2002 violence. Using a modified grounded theory approach for qualitative data, three principal distinctions between the Hindu and Muslim respondents were found: 1) perceptions of the responsibility of the Gujarat state government, 2) affect towards the experience of the riots, and 3) coping strategies utilized. The preliminary results suggest that affect and prejudices may differentially impact the process of cultural trauma and subsequent coping strategies. The study highlights how cultural identity shapes views of others and the discrepant processing of collective violence and trauma by individual members of two religious groups with a history of communalism.
\end{abstract}

Keywords: trauma, Gujarati riots, cultural trauma, Hindus, Muslims, identity

The violence that occurred in the Indian state of Gujarat in 2002 between Muslims and Hindus, starting with the train bombing in Godhra on February 27, claimed between 800 and 2000 lives, led to the destruction of hundreds of businesses, mass looting, gang-rapes of women, and forced hundreds of thousands to relocate to refugee camps (Human Rights Watch, 2002; Brass, 2003; Wilkinson, 2004; Mehta, Vankar, \& Patel, 2005). What sparked the train bombing has not been clearly proven (Human Rights Watch, 2002). Nearly all of the 58 victims who initially perished in the bombing were Hindu activists returning 
from the city of Ayodhya to advocate for the construction of a Hindu temple in place of the Babri Mosque, which had been torn down almost a decade earlier by Hindu extremists (Human Rights Watch, 2002).

While there is abundant literature chronicling Hindu/Muslim violence both pre- and post-partition (Brass, 2003; Puniyani, 1998, 2003; Rai, 1999; Wilkinson, 2004; Ashmore et al., 2001; Swami, 2001; Human Rights Watch, 2002), there are few studies that focus on the personal experiences of the individuals affected in such violence. However, a few studies indicate differences between the two religious groups in perceptions of the police (Rai, 1999), cultural symbols and Indian leadership (Sen, 2005), and even ratings of personal attributes in relation to aggressors and victims based on religious affiliation (Kanekar \& Merchant, 1982). One exploratory qualitative study conducted by Shankar and Gerstein (2007) interviewed four Muslims and five Hindus in Gujarat in an effort to formulate peace-building initiatives, but focused on what participants believed about possible solutions to violence rather than focusing on the participants' own reactions and processing of violence.

\section{Cultural Trauma}

The concept of individual trauma and the related concept of post-traumatic stress have been used to describe the reactions of those who were victims in the 2002 Gujarati riots (Bushna, 2002; Swami, 2002; Human Rights Watch, 2002; Sen, 2005). However, there is much disagreement about whether such traumatic symptom presentation constitutes Posttraumatic Stress Disorder (PTSD) in a cross-cultural context (Marsella, Friedman, Gerrity, \& Scurfield 1996). There is also the issue of utilizing culturally sensitive assessment measures (Wilson, 2007), despite there being at least one study using qualitative methods to validate PTSD criteria in India (Mehta, Vankar, \& Patel, 2005).

There are also significant limitations to understanding such events solely through the lens of the individual, particularly when the individual is part of a larger religious in-group or out-group. Culture is a mediating factor in understanding the behavioral and symptomological manifestations and prognosis of reactions to trauma (Green, 2003). A World Health Organization report highlights cultural risk factors-associated with politics, society, and communitythat play an important role in predicting collective violence (Bond, 2007). Bond (2007) believed that what has been neglected in understanding such violence is how culture is "a moderating role in exacerbating its members' degree of perceived distress" (p. 39). Perceived distress is not only related to the intrapsychic and biological realms of the individual, but can be affected by many systems that include, but are not limited to, family, religious, social, and political communities (Danieli, 2007; Drozdek, 2007; Hoshmand, 2007; Fairbank et al., 2003). The degree to which integration of these systems does not occur 
following violence may leave an individual susceptible to future experiences of trauma (Danieli, 2007). Hoshmand (2007) cautions that assumptions should not be made that all communities have the same stress levels before an identified traumatic event, especially for those groups that have been historically oppressed, nor should assumptions be made that all groups will have the same capacity to respond to the same treatment. Culture influences which negative experiences are shared with others, and which ones an individual keeps to him or herself (Drozdek, 2007).

Wilson (2007) argues that there cannot be an experience of psychological trauma with an exclusion of or indifference to cultural history. A traumatic event can lead to an extended experience of stress and emotional dysregulation, particularly if three criteria are met:

(1) the trauma is massive and damages the entire culture; (2) the nature of trauma causes the person to challenge the existing moral and political advocacy of prevailing cultural norms and values; (3) the trauma causes the individual to become marginalized within the culture and to be viewed as problematic, stigmatized, "damaged goods" or tainted by their experiences or posttraumatic consequences. (p. 25)

Thus, it may be useful to conceptualize trauma in a cultural context, as opposed to one based on an individual's symptoms. Cultural trauma is defined as "members of a collectivity feel[ing] that they have been subjected to a horrendous event that leaves indelible marks upon their group consciousness, marking their memories forever and changing their future identity in fundamental and irrevocable ways" (Alexander, Eyerman, Giesen, Smelser \& Sztompka, 2004, p. 1). A cultural trauma becomes even more significant when understanding that it poses a threat to individuals' personal identities in a given society (Alexander et al., 2004).

Shifts in Religious Identity for Hindus and Muslims Residing in India

According to Kakar (1996), a person who is "communal" in an Indian context - and therefore has a shared religious identity - can be defined as:

One whose exclusive attachment to his or her community is combined with active hostility against other communities which share its geographical and political space. Communalism not only produces an identification with a religious community but also with its political, economic, social, and cultural interests and aspirations. (p. 13). 
Kakar picks up on the historical tension that has existed between Hindus and Muslims in the Indian context. A broader social-psychological-theoretical formulation, of which Kakar's communalism is an example, is Tajfel's Social Identity Theory, which posits that an in-group's distinctive character is defined and maintained principally in relation to relevant out-groups (Brown \& Zagefka, 2005; Tajfel \& Turner, 1986).

There is also a more recent literature describing shifts in religious identity and in-group/out-group positioning for Hindus and Muslims in the communal context. A new Hindu identity based on nationalism, Hindutva, has emerged in recent years (Stavenhagen, 1996). In stark contrast to the traditional practices of Hindus, the new movement ignores practices such as rigid caste divisions (Ashmore et al., 2001; Stavenhagen, 1996). Muslims, as a minority within India (154 million Muslims compared to 930 million Hindus), are invariably affected by the new Hindu identity. One possible result of this new movement may be that urban Muslims earn lower wages than any other religious group in the country, and Urdu (spoken primarily by Muslims) has become a displaced language that has further alienated Muslims from the job and public sector (Puniyani, 1998). In reaction to Hindu communalism, a broad Muslim identity has become increasingly endorsed (Puniyani, 1998). These shifts have laid the groundwork for religious conflict and violence and provide the backdrop for how individuals may process violence within a cultural framework.

\section{Indian Diaspora in the United States and Collective Identity}

Immigration to the United States opened up to professional and educated Indians in 1965 with the passing of the Immigration Act of 1965 (Durvasula \& Mylvaganam, 1994; Quddus, 2005; Prashad, 2000). Acculturation may have been even more difficult for these immigrants as members of a collectivist culture of origin (Wong \& Wong, 2006; Durvasula \& Mylvaganam, 1994). After a literature review, Bhugra (2005) concluded that migrants who move from a collectivistic culture to an individualistic one, where there is little social support, experience increased stress. Changes due to modernization have led to geographic displacement for the purpose of seeking financial opportunities as well as associated feelings of rootlessness resulting from loss of friends and family and cultural values (Kakar, 1996; Ashmore, Jussim, \& Wilder, 2001). Humiliation is not an uncommon feeling when non-Western citizens view the inequity in power and financial structures in comparison to their host country (Wong \& Wong, 2006). Feelings of isolation for immigrants can also stem from perceived hostility from other Americans and the West in general (Wong \& Wong, 2006).

To counter feelings of marginalization, Indians have formed student organizations at universities, which have grown in number and have become more 
specific to language, locality, and religion (Quddus, 2005). Spirituality grew in importance as Indian parents worried that their children would adopt the morals of the new (American) society (Prashad, 2000; Quddus, 2005). Another reason for Indians, particularly Hindus, to gravitate towards spirituality is the notion that they are somehow inherently advanced in this domain (Sen, 2005). This is typically a view held by Western individuals outside of Indian society, perpetuated in the era of colonialism (Sen, 2005).

The Vishnu Hindu Parishad of America (VHPA), along with affiliated organizations such as the Hindu Student Council, have put together youth camps that have been accused of portraying distorted views of Indian history and culture (Quddus, 2005; Prashad, 2000). These organizations have held world forums that have used scare tactics by advancing the notion that Indian Muslims threaten the physical safety and identity of Hindus (Puniyani, 2003). Many temples are run by the VHPA and serve to function as monetary supports and to propagate the idea of India as a Hindu nation (Quddus, 2005; Prashad, 2000). These factors, including funding from abroad, distortions of history, identification with a traditionally allocentric culture, and marginalization may color perceptions and experiences of the 2002 Gujarati riots for recent Indian immigrants.

\section{Purpose}

Despite the increasing literature suggesting that changing identities based on religion may underlie the riots, there is a dearth of psychological research in this area. While there is theoretical literature on how cultural traumas develop, it remains unclear how such trauma affects individuals psychologically, specifically in an Indian context. Furthermore, while the concepts of cultural trauma and collective identity are interrelated, the nature of the relationship is unclear. To our knowledge, there are no studies that have looked at how religious identities are negotiated and re-negotiated in the Indian Diaspora in the United States following religious riots. The purpose of this qualitative study was to better understand how such identity is negotiated, and its interplay with collective trauma, as well as in- and out-group affiliations and prejudices. Identifying cultural trauma in the Indian Diaspora may lead to the development of more appropriate mental health interventions and a better understanding of the psychological sequelae of exposure to similar events.

\section{Hypothesis}

Given the religious affiliations of those who perished in the Godhra train bombing (Hindu) and its aftermath (predominately Muslim), our tentative hypothesis is that Gujarati Hindus experienced the Godhra train bombing as 
a cultural trauma, while Gujarati Muslims instead experienced only the pogrom that followed as a cultural trauma. Our hypothesis is in line with Volkan's (2001) concept of "chosen trauma" where distinct groups based on collective identity designate which events are traumatic and which ones are not. Chosen traumas are negative experiences that are the basis of group-level humiliation and unprocessed grief (Volkan, 2001). A trauma can help to strengthen or deteriorate a community or identity, usually some combination of the two (Alexander, 2004). Therefore, another distinction we think may become apparent is that the Godhra train bombing helped to unify and strengthen the religious and nationalistic identities of Gujarati Hindus, while for Muslims we would venture to say that it may have strengthened their religious identity, and yet weakened their national identity as Indians.

\section{Method}

\section{Participants}

Inclusion criteria for participants were as follows: interviewees had to be individuals who were at least 18 years of age and identified themselves as either Gujarati Muslims or Hindus who were in the state of Gujarat, India during the riots (February 27-April 30, 2002). All participants currently resided in the U.S. The sample size was a total of 17 participants, 10 Hindus and 7 Muslims. Of the 10 Hindu participants, eight were male and two were female. All of the Muslim participants were male.

\section{Demographics of the Hindu Participants}

The Hindu participants averaged $30.6[S D=9.9]$ years in age. The participants averaged $1.16[S D=1.41]$ years residency in the United States, with half having permanent residency in the United States. With respect to highest education completed, $20 \%$ were high school graduates, $10 \%$ had some college credits, $40 \%$ were college graduates and $30 \%$ had graduate credits. Regarding employment, $40 \%$ of the Hindu participants were students, $30 \%$ were employed and $30 \%$ were unemployed at the time of the interview. Ten percent of the participants did not attend religious services, $20 \%$ attended one to ten times a year, $40 \%$ attended on a monthly basis and 30\% attended weekly. Half of the participants read religious scripture one to ten times a year, $10 \%$ read on a monthly basis, $20 \%$ read weekly while the remaining $20 \%$ read daily. Seventy percent of the participants attest to being members of a religious or political group. 


\section{Demographics of the Muslim participants}

The Muslim participants averaged 27.6 [SD =9.0] years in age. The participants averaged $5.05[S D=7.63]$ years residency in the United States, with $29 \%$ having permanent residency in the United States. Fourteen percent of the participants did not complete high school, 14\% graduated high school, 29\% had some college credit, $14 \%$ graduated college, $29 \%$ attended graduate school. Regarding employment, 29\% identified themselves as students, 57\% unemployed and 14\% employed. Fourteen percent of the participants attended religious service and read scripture one to ten times a year, $14 \%$ did so on a weekly basis and $72 \%$ daily. Lastly, none of the Muslim participants were affiliated with any religious or political groups.

\section{Materials}

The semi-structured interview protocol was developed using relevant topics found in the literature such as social identity (i.e., "Please describe what it means to be Indian"); role of government (i.e., "Do you think that local and state governments aided or deterred the riots? In what ways?"); acculturation (i.e., "What are some differences between Gujarati culture and American culture? Similarities?"); perceptions of the other religious group (i.e., "How do you see your community's responsibility in the violence?, What about the other community," etc.); proposed solutions (i.e., "What role do you think that NonResident Indians (NRIs) can play in preventing this from occurring in the future?"); and coping strategies (i.e., "How have you been able to put this experience behind you, did you talk to anyone about your experience before, how did your family deal with this experience," etc.). The interview protocol was further refined after two pilot interviews with individuals that met the inclusion criteria. Due to the fact that the interviews were conducted in a semi-structured format, the interviewer attempted to ask follow-up questions using terms that the participant used over the course of the interview in an effort to reduce bias in gathering data between the two groups (Cope, 2004). The interviews ranged from 40 to 117 minutes ( $M=67$ minutes, $S D=19.7$ minutes).

\section{Procedure}

Participants were a convenience sample, recruited using two primary methods. The first was the solicitation of potential participants outside of Indian stores in central New Jersey. All of the Hindus were recruited using this method. The Muslim sample was a snowball sample, where information about the study was sent from a posting on the internet to an activist and by contacting a leader in the Muslim Gujarati Association located in the United States; these two sourc- 
es yielded seven participants. Individuals who were interested in participating gave us their contact information for further information regarding the study. They were told their participation would consist of the following procedure: receiving the consent form and having a chance to ask questions, filling out a demographic questionnaire and answering questions related to their experience of the 2002 Gujarati riots in an interview format that required audio taping. All ten of the Hindu participants and three of the Muslim interviewees lived in the New York/New Jersey area and were interviewed in person. Four of the Muslim participants lived in Illinois and were interviewed via phone.

Interviews were conducted either at the participants' homes or at a meeting site that was mutually agreed upon by the participant and the interviewer. The sole interviewer was a first generation Hindu Indian-American male who was born and brought up in Central New Jersey and who spoke English and Gujarati (the interviews were conducted mostly in English but occasionally in Gujarati). Participants were offered \$20 in compensation for participating upon signing the consent form.

\section{Data Analysis}

All interviews were recorded using a digital recorder and subsequently transcribed verbatim. Thematic content analysis was conducted using modified grounded theory approach (Strauss \& Corbin, 1998; Coolican, 2004; Henwood \& Pidgeon, 1992) with NVivo 7 software. Grounded theory is based on an inductive process where information is analyzed with few, if any, a priori hypotheses or theory; in fact, grounded theory aids in generating or developing theory (Strauss \& Corbin, 1998).

Two stages of grounded theory, open coding and axial coding, were implemented. Open coding consists of reading the data line by line and highlighting discrete units of interest (Strauss \& Corbin, 1998). Once a segment of the data is highlighted, it is given a short label that attempts to capture its essence. Parts of the interviews were then read by a coding group of qualitative researchers led by a senior expert in qualitative methodology and six graduate students. The group served as an audit trail (Lincoln \& Guba, 1985), helping to verify the coding and reduce individual bias. The principle investigator, however, did the majority of the coding individually, using group meetings for verification and to increase validity.

The second step, axial coding, is accomplished by taking the individual codes and grouping them into larger conceptual categories, or themes (Strauss \& Corbin, 1998). This process was accomplished by a process of linking open codes that were conceptually were related for each of the two religious groups. Once these steps were taken, the next step was to compare the themes and 
categories that developed between the two groups (Hindus and Muslims). A summary description of the major findings was created to highlight differences in how Hindus and Muslims perceived the 2002 Gujarati riots.

\section{Results}

\section{Themes Identified in Interviews with Hindu Participants}

There were 46 sub-themes that emerged during open coding of the responses by Hindu participants. Forty-three of these sub-themes were grouped into 11 themes. Only themes that occurred at least eight times are described below, ordered by the frequency in which they occurred.

\section{Theme 1: Muslims as Aggressive Individuals}

The theme describes the sentiment that Muslims are violent by nature. As one participant put it, "They are 100\% more aggressive. You took the right word, aggressive. They're any time more violent and more aggressive. They just need a reason to be violent. They are always ready with the swords and all that to take revenges." Other references talked about Muslim violence after India-Pakistan cricket matches and Muslims sponsoring terrorism, as well as explaining that Muslims are meat-eaters, and therefore more prone to violence. Some participants referred to historical altercations with Muslims as the perpetrators:

Anytime you see the history of India, the Muslims come from Durbastan, Afghanistan. They destroy our mandirs, temples. They don't respect us, they don't give us [any] right(s). You take any Muslim king from Akbar to Aurengzeb ... [they] just broke the temples. They don't respect our God, they broke the statues of our God. They only want to destroy everything.

\section{Theme 2: Other Reasons for Violence}

This theme refers to reasons for violence that do not involve Muslims as the perpetrators of the riots. Some participants stated that the Godhra train burning was what instigated the violence, such as: What is the exact reason for the violent for the riots? Some Hindu people were coming by the train from Ayodhya to Baroda or any Godhra right? In between Godhra, they were the community that was burned by the Muslim peoples.... in train.

There were also respondents that blamed Hindu political leaders for the violence, although within this group, not all saw it as a bad thing, "He (Modi) 
also think that, "I'm Hindu. Why should I-why I can't see that my Hindu brother was killed by Muslim?" So, he also gives some relief to do right, to do this violent thing for Hindus."

\section{Theme 3: Muslims as the Other}

A major aspect that makes up this theme discusses the separation between the two religious communities: "they (Muslims) don't want to live in our country, they don't want to dissolve in us (Hindus). They want to be distinct so I feel that they hate us." Most references refer to before the violence, but one is cited as a result of the 2002 violence. Both references that Muslims are disloyal to India are sports examples of Muslims rooting for Pakistan against India in cricket games,

But $90 \%$ of Muslims say they don't have proud [sic] of the country just like one example is that when there is an international cricket or one-day test match is going on and suppose Pakistan wins the match then all the Muslims [sic], $90 \%$ of Muslims they celebrate that our country, Pakistan wins. Muslims win and Indians defeat ... . . . Why Hindus say that if India wins then they celebrate, otherwise no? Because they have proud [sic] of their country.

\section{Theme 4: Hindus are Passive}

There were interviewees that made the point that they thought Hindus are non-violent, "so in Gujarati, they say that Hindus, especially for Gujaratis that they don't cause any trouble." Some participants spoke about Hindus not retaliating in any way to perceived Muslim aggression, "There wasn't anything in our city or even most of the city but in one city the leaders who were involved had said we took action, why haven't you? Do you wear bangles?" Unlike the previous example, there is also pride in being non-violent, "so that is what I am proud of . . . that I belong to a country who does not believe in violence. I belong to a country who still though has nuclear arms, though possesses nuclear arms doesn't use against them."

\section{Theme 5: Hindus are powerful}

"Hindus are powerful" theme illustrated the sentiment that Hindus gained power in retaliating against Muslims. An example of a response that was subthemed "Hindu revenge" is, "the Hindus that really got the beating in all these years. When there was a party which was a strong Hindu believing party ... they 
came into power they took the revenge." Some participants made the point that they saw solidarity in the Hindu community as a positive result of the 2002 violence.

\section{Theme 6: Hindu-Muslim Unity}

There were some respondents that felt that Muslims were unfairly maltreated in 2002. For example, "it's not good. Why destroying the stock and that people did not-they have done nothing. They don't have any connection with when that Godhra attack, that's right?" An example that captures the idea of togetherness and interdependence of the two communities is, "Hindus and Gujaratis [Muslims] together live like brothers in the city. But during riots often in both communities little problems develop. It's like one father has two sons ... the sons have many fights, but live together, they need each other."

\section{Themes Identified in Interviews with Muslim Participants}

There were 49 sub-themes that were used when using open coding when analyzing responses of Muslim participant. Forty-seven of these sub-themes were grouped into nine themes. Similar to the previous section, only themes that occurred at least eight times are described below, ordered by the frequency in which they occurred.

\section{Theme 1: Muslims as a Separate Group}

The first theme describes how many of the Muslim interviewees made reference to their religious community as separate from the dominant Hindu majority, often not by their choice. Muslim participants acknowledged how they have been created as an out-group for the Hindu majority to despise, helping to unify the Hindu in-group. One participant reasoned that the government incited the violence to, "unite the Hindus and this would make things easier for the government to implement. With Hindus and Muslims fighting, they figured the Hindus would become one." Three participants made reference to Hindus believing that Muslims are foreigners due to their religious affiliation.

Three Muslim participants also described how Hindus and Muslims lived peacefully, and how that changed after 2002, "we (Hindus and Muslims) played together, and after violence. ... there is more distance between us, and we can't get together after violence."

A couple of participants referred to how in Gujarat, Muslim localities are referred to as Pakistan, and Hindu localities are called India. One participant said, "in Gujarat, particularly what I noticed was that there was this separation, 
a physical separation between Muslims and Hindus." Another participant spoke about the necessity for segregation from Hindus, "after 2002, we have to keep distance from Hindus because they can attack any time."

\section{Theme 2: Government Anti-Muslim Bias}

Nearly half $(47.8 \%)$ of the references that make up the theme concern atrocities and biases committed by the Gujarati police against the Muslim community. The police not only led Hindu mobs, but some participants also described police inactivity, "(I) heard that Muslim leaders called the police and all these people, but nobody came. . . no one helped us."

All seven participants named some aspect of the Gujarati government escalating the violence. A couple of respondents took this even a step further and believed that the Godhra train bombing was a conspiracy by the Gujarati government, "(the Sangh) kill their own people, rise anger (in the Hindu community), kill Muslims. Already planned, the people and police will help, the group will help, and the public will join them." There is also a sentiment that the government has double-standards when dealing with the two religious communities, "if you (Muslims) make a group, you are a terrorist group, but the same group, or same community activities running by Hindus, then that's national activities, so called, even if they are ... training (people) how to use weapons [sic]."

\section{Theme 3: Hindus Are Against Muslims}

Within this theme, there were four references to the use of propaganda by the Gujarati government and right-wing Hindu groups to demonize the Muslim community. One example of propaganda is, "it's the same government that-the same Chief Minister. . . gives political speeches that these were the Muslims that want to kill me and I am the .. . protector of Hindus." Another example is, "they (Sangh) mislead people and scare people by saying that Muslims go to the Masjid and are taught to fight against Hindus. And that's why they see us with hatred." Both examples are illustrations of the government and the Sangh attempting to create fear in the Hindu community, hoping to unite and mobilize them against Muslims. Three participants explicitly believe that NRI funds were used to fund the pogrom, and hope that in the future, NRIs will do more research into what their money is allocated for.

\section{Theme 4: Dejection}

The theme "Dejection" centers around Muslim participants' sentiments of both helplessness and hopelessness; affect that is not discussed at all in the Hindu 
sample. Four participants expressed feeling helpless. One participant talked about emotions he felt but could not do anything about resolving them:

yeah you feel angry. You feel helpless and sometimes you feel that, okay I will also go out and kill everybody. I will also go out and burn every single business of Hindus, but you are helpless because. . . . the entire government is against you."

Another participant sadly exclaims, "[we had] given up any hope of getting through this event alive. We never thought we would see such a thing and after seeing it, we feel that life is pretty much over."

\section{Theme 5: Coping}

The Muslim participants offered a wide variety of coping strategies that they used to deal with the 2002 pogrom. The most commonly used strategy was having faith in Islam. What they meant by faith was not homogenous, as one participant used it in a passive way:

Islam still teaches to forget what happened. Get on with your life, earn money, take care of your family. Islam says that Allah will take care of punishing the wrong-doers, you do not have to take that responsibility upon you.

Another participant used his faith to spread awareness, "what I'd do personally is talk about Islam to the people who has no idea what Islam is."

A couple of participants used strategies aimed at distancing themselves from the event by saying that they have tried to forget what happened, and others simply try to avoid thinking about it. Unlike his family, one participant believed that he was able to speak about his experience in an interview format in the present study, "because I had joined this group where there were other people who had similar experiences, worse experiences actually and that were willing to talk about it out in the open." The same group was also involved in seeking social justice as they were one of the organizations that successfully petitioned against the Chief Minister of Gujarat, Narendra Modi, entering the United States.

\section{Theme 6: Negative or No Affect}

The theme "Negative or No Affect" consists of statements that encompass such feelings as fear, shock, and worry. One bewildered participant exclaimed, "Not even in our dreams did we think that such a thing could happen in our Gujarat." 
Another participant talks about the RSS, "the next time they are going to try this elsewhere. Those things really scare me. That's why I really worry about India."

There were three instances where it seemed that respondents attempted to avoid discussing their affect. Also, there were cases where participants would just say they felt bad, and would not elaborate any further. While this could be due to not having the words to describe their affect in English, or a cultural dissonance where negative feelings are not discussed or ruminated upon, it could also be a coping mechanism to avoid opening up troubling, or even traumatic, memories.

\section{Discussion}

The present study sought to understand the process of trauma in Hindus and Muslims who lived in Gujarat during the 2002 violence, and to assess whether the two groups coped with the event in culturally similar or distinct ways after immigrating to the U.S. subsequently. The results of the study indicate that the Muslim sample may have experienced the post-train bombing violence as a cultural trauma, whereas the Hindu sample did not. Conversely, a few Hindu participants may have experienced the Godhra train bombing event as a cultural trauma, while the Muslim sample did not. The results support Alexander's (2004) idea that cultural trauma can only impact a group if an experienced event is followed by negative feelings due to the event's effect on the group's cultural identity. Moreover, these findings serve as examples of Volkan's (2001) concept of "chosen trauma." Chosen traumas are reactivated when an event occurs that is perceived to threaten a collective identity (Volkan, 2001; Kakar, 1996), which appears to have happened with Hindus during the Godhra train bombing and for Muslims with the violence that followed.

The second major finding that emerges from the data is that the Muslim sample exhibited feelings of hopelessness and helplessness in regard to their personal and community situations during the riots, after the riots, and in their beliefs about the future. These emotions were completely absent in the Hindu group. A few Muslim participants had trouble labeling their emotions, while the Hindu interviews were remarkably lacking in emotion when describing the events of the riots. The latter occurrence may have been due to any of the following factors: group-level guilt, the event not being considered a cultural trauma, or net-beneficial consequences of the violence for the Hindu in-group (in terms of their increasing strength and unity). Although the Muslim participants were voluntary immigrants to the U.S., their experience was much more in line with the experiences of refugees (Baron, Jensen \& de Jong, 2003). For one, they were fearful and anxious about the losses they endured (not only material, but also in terms of relationships to others and affiliation to Gujarat). 
Furthermore, they were angered by the events that led to their current situation, and exhibited feelings of both hopelessness and helplessness (Baron et al., 2003).

Also of note was the fact that the Hindu participants used psychological distancing more often than the Muslim interviewees. For example, many of the Hindu participants rationalized the violence against Muslims using perceived notions of historical discrimination and violence perpetrated against them by Muslims. In contrast, the Muslim interviewees cited faith in their religion, the desire to seek social justice, and group processing with others, such as their families and other affected individuals, as means of coping. Compared to Muslim participants, Hindu participants showed a relative lack of affect or coping/processing. It is possible, but speculative, that the negative characteristics assigned to Muslims by the Hindu participants were indicative of underlying feelings of guilt as members of the perpetrator group in the 2002 Gujarati genocide.

Recent research supports this idea that defensive projection used by ingroup members to rationalize or disavow negative characteristics ascribed to them is a result of suppression (Newman \& Caldwell, 2005). The most relevant evidence that the Hindu participants used projection, as a result of suppression, is the fact that many believed that more Muslims died as a result of the violence in Gujarat, and yet they stereotyped Muslims as the more aggressive actors. The very nature of a cultural trauma can overwhelm a group's previous defense mechanisms, thus requiring it to adopt new mechanisms. Such new coping strategies can in turn enhance the group's ability to justify the use of future violence in retaliation for their grievances (Young-Bruehl, 1996).

A related finding in the present study is the apparent conflict within the Hindu sample about their collective identity. Many participants described Hindus as a peaceful group, while Muslims as violent and united. Yet at the same time, they also appeared to take pride in the fact that Hindu identity and unity became more solidified in the wake of the Gujarati riots. Some of the Hindu participants seemingly even envied two attributes that they ascribed to the Muslim community: aggressiveness and unity. Such an idea of envying the out-group runs contrary to the notion of defensive projection. In Glick's (2005) explanation of scapegoats, he surmises that "it is precisely the perceived power of a group (not its perceived weakness) that makes [that out-group] likely to be scapegoated ... earlier views dismissed perceptions of the scapegoat's power and malevolence as mere projections" (p. 254). A couple of Hindu participants described their communities' lack of violence in previous communal riots as an indication of their passivity, and thus, their weakness. The general lack of negative affect expressed by the Hindu interviewees, as discussed previously, may be more indicative of the perceived positive outcome of the violence, namely that Hindus exhibited their strength vis-à-vis the Muslim community. This hypoth- 
esis is more in line with Glick's (2005) idea that "scapegoat movements address frustrated needs for esteem, belonging, and transcendence by reasserting the in-group's superiority. . . . Security, physical well-being, and hope are addressed by identifying and combating the "enemy" that has putatively caused the ingroup's misfortunes" (p.255).

Additionally, this study provides evidence to support Tajfel's Social Identity Theory as the vast majority of the Hindu participants (90\%) distinguished themselves from the Muslim out-group by attributing negative characteristics to the latter. Muslims were thought of as polygamous, misogynistic, disloyal to India, and akin to foreigners, etc. The most common negative attribute cited by Hindu participants was that Muslims are aggressive, which they often attributed to their non-vegetarian diet. Based on the results of the study, it may be speculated that for the Hindu participants, an in-group based on religious affiliation may have been further reinforced during the Godhra train bombing, given that half of the Hindu participants named it as the primary cause of the 2002 Gujarati violence, and that three of those five participants stated their belief that Muslims instigated the incident. For Muslim participants, an in-group seemed to center on systematic discrimination and aggression by Hindus exemplified by the aftermath of the Godra Train burning.

Brown and Zagefka (2005) described the conclusions that Brewer drew from her own research on inter-group relations and identity formation, namely that there were several factors that contributed to more positive in-group self-regard, and in turn, to the devaluation of an out-group. Some of these relevant factors cited were a low degree of cultural and societal stratification within broader society; opposing interests or threats to the in-group's integrity; and an in-group's attempts to create a broader and more unified identity in order to achieve a common purpose. However, Indian society is characterized by an enormous degree of social complexity, given that numerous hierarchies around gender, marital status, age, number of children and their gender, not to mention the nebulous caste system, all govern family and broader social relations. Thus, in order to counter these in-group Hindu sub-divisions, the 2002 Gujarati violence represents an attempt to unify all Hindus under a common identity. This appears to have been achieved by reducing societal complexities across traditional Hindu sub-groups, and by further demarcating a villainous out-group, the Muslims.

In understanding the differing experience of Hindus and Muslims, it is also important to note that the trauma process can involve many segments of society (Alexander, 2004). Muslim participants elaborately described how various sectors of society were involved in their experience in both debilitating and supportive ways, such as in the legal and political arenas (false witnesses used by the government, government complacency, police participation in the massacre), aesthetic (the documentary "Final Solution" which portrayed the 2002 
Gujarati as a genocide against the Muslim community), mass media (magazines such as Tehelka, which interviewed various Hindu perpetrators who openly admitted to the atrocities they committed), and the state bureaucracy (which subsequently appointed commissions that sought to investigate government complicity in the riots). In contrast, the Hindu participants believed that the lo$\mathrm{cal}$ and state governments acted to deter and mitigate malevolent forces in the 2002 Gujarati violence. The Hindu participants to a lesser degree articulated having experienced the process of cultural trauma, thus further substantiating that the Gujarati violence (events subsequent to the Godhra train burning) was not perceived as a cultural trauma by Hindus.

\section{Limitations of the Study}

The study was undertaken with the intention of generating theory and hypotheses about cultural trauma in an Indian context using grounded-theory analysis. Thus, the investigation is intended to present the groundwork for hypotheses that must be tested through future studies in order to refine and validate the conclusions drawn here. A major limitation of the study is the small sample size. Given that there were only two females in the Hindu sample and none within the Muslim sample, gender differences may not have been captured; therefore, the results are overall more reflective of males' experience. Furthermore, the study may have been affected by selection bias, given the different strategies employed to recruit the participants across the two groups.

Another limitation involves the effect of the interviewer's ethnic identity on the results. As is often the case in research, experimenter characteristics are ignored, being neither reported within the study, nor discussed for their possible influence on the participants and the study's subsequent results (Kazdin, 2003; Anderson, 1993). The sole investigator's religious affiliation (Hindu) was easily deduced by South Asians due to his first and last names and therefore, we believe it played a role in influencing participant responses. Anderson (1993) discussed the willingness of members from the majority group to participate in studies, due to a lower degree of fear that the researcher will exploit them. It is our opinion that even the Hindu participants that agreed to be interviewed would not have been able to speak at ease about the aggressiveness of Muslims and perceived injustices by Muslims upon their community without a perceived similarity with the interviewer. On the other hand, Muslim participants may have been able to discuss with him more openly their feelings of vulnerability without the perceived obstacle of an out-group interviewer.

Further studies with larger samples and more equal representation of women need to be conducted in order to validate the findings of the present study. To account for the question of acculturation, it may be useful to compare a non-Resident Indians sample to a sample still living in Gujarat. Some of the 
slum areas in Gujarat's cities were the worst affected during the 2002 Gujarati violence (Human Rights Watch, 2002), and many participants in those areas are to a greater degree living with the direct consequences of the aftermath even today. As Human Rights Watch (2002) suggests, many segments of Indian society were involved and affected by the violence. Therefore, a stratified sample with respect to socio-economic status and geographical location might contribute to a more accurate understanding of the effects of the 2002 Gujarati riots. Furthermore, it would be important to collaborate with researchers (both Muslim and Hindu) in Gujarat who could interview participants, with the assumption that their fluency with local dialects spoken, and intimate knowledge of local cultural specificities, would lead to more trust by interviewees. In turn, the greater levels of trust that participants feel may lead them to be more forthcoming with their emotions and opinions concerning the 2002 Gujarati riots.

\section{Reducing Communal Tension}

One way to reduce intergroup bias is the framework of recategorization (Gaertner \& Dovidio, 2005). Re-categorization occurs when the salience of in-group out-group designations is minimized by the creation of and adherence to a larger, more encompassing identity (Gaertner \& Dovidio, 2005). Instead of attempting to classify Muslims as non-Indians, politicians of all religious backgrounds should seek to unite Indian citizens under a secular national banner. As Gaertner \& Dovidio (2005) pointedly explain, "perceptions of group boundaries such as 'us' and 'them' can be transformed into a more inclusive 'we"' (p. 77).

In asking Gujarati Muslims and Hindus what they felt could decrease animosity between the two groups, Shankar and Gerstein (2007) reported that responses included increasing social interaction between the two groups by way of mutual participation in community events and activities such as religious festivals may help to decrease feelings of tension. There is promising research that suggests that intergroup dialogues in which members of various groups are encouraged to speak directly about their feelings related to prejudice and stereotypes of the other groups, can effectively contribute to long-term behavioral and attitudinal change (Stephan \& Stephan, 2005). The advantage of intergroup dialogues versus other interventions is that it focuses more on expressing affect, rather than didactic forms of multicultural education and diversity training (Stephan \& Stephan, 2005). As seen in this study, there were stark differences in emotions expressed among Hindus and Muslims, and it may be useful for both sides to be aware of how the other religious group feels when misperceptions reinforce communal stereotypes and prejudices. This research may be a first step in highlighting such misperceptions at the prejudice, affect, and processing of trauma levels. 


\section{References}

Alexander, J.C., Eyerman, R., Giesen, B., Smelser, N.J., Sztompka, P. (2004). Cultural trauma and collective identity. Berkeley: University California Press. http://dx.doi. org/10.1525/california/9780520235946.001.0001

Anderson, M.L. (1993). Studying across difference: race, class, \& gender in qualitative research. In J.H. Stanfield B \& R.M. Dennis (Eds.), Race \& ethnicity in research methods (pp.39-52). Newbury Park: Sage Publications.

Ashmore, R.D., Jussim, L., \& Wilder, D. (Eds.). (2001). Social identity, intergroup conflict, and conflict reduction. New York: Oxford University Press.

Baron, N., Jenson, S.B. \& de Jong, J.T.V.M. (2003). Refugees and internally displaced people. In B.L. Green, M.J. Friedman, J.T.V.M. de Jong, S.D. Solomon, T.M. Keane, J.A. Fairbank, B. Donelan \& E. Frey-Wouters (Eds.), Trauma interventions in war and peace: prevention, practice, and policy (pp.243-270). New York: Kluwer Academic/Plenum Publishers. http://dx.doi.org/10.1007/978-0-306-47968-7_11

Bhugra, D. (2005). Cultural Identities and Cultural Congruency: A New Model for Evaluating Mental Distress in Immigrants. Acta Psychiatrica Scandinavica, 111, 84-93. http://dx.doi.org/10.1111/j.1600-0447.2004.00454.x

Bond, M.H. (2007). Culture and Collective Violence: How Good People, Usually Men, Do Bad Things. In B. Drozdek \& J.P. Wilson (Eds.), Voices of Trauma: Treating Psychological Trauma Across Cultures (pp.27-58). New York: Springer.

Brass, P. (2003). The production of Hindu-Muslim violence in contemporary India. Seattle: University of Washington Press.

Brown, R. \& Zagefka, H. (2005). Ingroup affiliations and prejudice. In J.F. Dovidio, P. Glick \& L.A. Rudman (Eds.), On the nature of prejudice: 50 years after Allport (pp.5470). Malden: Blackwell Publishing. http://dx.doi.org/10.1002/9780470773963.ch4

Bushna, D. (2002, May 11-24). A relentless hate campaign. Frontline, 19(10). http:// www.frontlineonnet.com/fl1910/19100040.htm

Coolican, H. (2004). Research methods and statistics in psychology 4th edition. Hodder \& Stoughton: London.

Cope, C. (2004). Ensuring validity and reliability in phenomenographic research using the analytic framework of a structure of awareness. Qualitative Research Journal, $4(2), 5-18$.

Danieli, Y. (2007). Assessing Trauma Across Cultures from a Multigenerational Perspective. In J.P. Wilson \& C.S. Tang (Eds.), Cross-Cultural Assessment of Psychological Trauma and PTSD (pp.65-89). New York: Springer. http://dx.doi. org/10.1007/978-0-387-70990-1_4

Drozdek, B. (2007). The Rebirth of Contextual Thinking in Psychotraumatology. In B. Drozdek \& J.P. Wilson (Eds.), Voices of Trauma: Treating Psychological Trauma Across Cultures (pp.1-26). New York: Springer.

Durvasula, R.S. \& Mylvaganam, G.A. (1994). Mental health of Asian Indians: Relevant issues and community implications. Journal of Community Psychology, 22, 97-108. http://dx.doi.org/10.1002/1520-6629(199404)22:2<97::aidjcop2290220206>3.0.CO;2-\#

Fairbank, J.A., Friedman, M.J., de Jong, J.T.V.M., Green, B.L. \& Solomon, S.D. (2003). Intervention Options for Societies, Communities, Families, and Individuals. In B.L. Green, M.J. Friedman, J.T.V.M. de Jong, S.D. Solomon, T.M. Keane, J.A. Fairbank, B. Donelan \& E. Frey-Wouters (Eds.), Trauma Interventions in War and 
Peace: Prevention, Practice, and Policy (pp.57-72). New York: Kluwer Academic/ Plenum Publishers. http://dx.doi.org/10.1007/978-0-306-47968-7_4

Gaertner, S.L. \& Dovidio, J.F. (2005). Categorization, recategorization, and intergroup bias. In J.F. Dovidio, P. Glick \& L.A. Rudman (Eds.), On the nature of prejudice: 50 years after Allport (pp.71-88). Malden: Blackwell Publishing. http://dx.doi. org/10.1002/9780470773963.ch5

Glick, P. (2005). Choice of Scapegoats. In J.F. Dovidio, P. Glick \& L.A. Rudman (Eds.), On the Nature of Prejudice: 50 Years After Allport (pp.244-261). Malden: Blackwell Publishing. Green, B.L. (2003). Trauma Stress and its Consequences. In B.L. Green, M.J. Friedman, J.T.V.M. de Jong, S.D. Solomon, T.M. Keane, J.A. Fairbank, B. Donelan \& E. Frey-Wouters (Eds.), Trauma Interventions in War and Peace: Prevention, Practice, and Policy (pp.17-32). New York: Kluwer Academic/Plenum Publishers.

Henwood, K.L. \& Pidgeon, N.F. (1992). Qualitative research and psychological theorizing. The British Journal of Psychology, 83, 97-111. http://dx.doi.org/10.1111/j.20448295.1992.tb02426.x

Hoshmand, L.T. (2007). Cultural-Ecological Perspectives on the Understanding and Assessment of Trauma. In J.P. Wilson \& C.S. Tang (Eds.), Cross-Cultural Assessment of Psychological Trauma and PTSD (pp.31-50). New York: Springer. http:// dx.doi.org/10.1007/978-0-387-70990-1_2

Human Rights Watch. (2002). We have no orders to save you: State participation and complexity in communal violence in Gujarat, 14(3), 1-68.

Kakar, S. (1996). The colors of violence: Cultural identities, religion, and conflict. Chicago: The University of Chicago Press.

Kanekar, S. \& Merchant, S.M. (1982). Aggression, retaliation, and religious affiliation. The Journal of Social Psychology, 117, 296-296. http://dx.doi.org/10.1080/0022454 5.1982 .9713439

Kazdin, A.E. (2003). Research Design in Clinical Psychology, 4th Edition. Boston: Allyn and Bacon.

Lincoln, YS. \& Guba, EG. (1985). Naturalistic Inquiry. Newbury Park, CA: Sage Publications.

Marcella, A.J., Friedman, M.J., Gerrity, E.T., \& Scurfield, R.M. (1996). Ethnocultural aspects of Posttraumatic Stress Disorder: Issues, research, and clinical applications. American Psychological Association: Washington, D.C. http://dx.doi. org/10.1037/10555-000

Mehta, K., Vankar, G., \& Patel, V. (2005). Validity of the construct of Post-Traumatic Stress Disorder in a low-income country: Interview study of women in Gujarat, India. British Journal of Psychiatry, 187, 585-586. http://dx.doi.org/10.1192/ bjp.187.6.585

Newman, L.S. \& Caldwell, T.L. (2005).Allport's "living inkblots": The role of defensive projection in stereotyping and prejudice. In J.F. Dovidio, P. Glick \& L.A. Rudman (Eds.), On the nature of prejudice: 50 Years after Allport (pp.377-392). Malden: Blackwell Publishing. http://dx.doi.org/10.1002/9780470773963.ch23

Prashad, V. (2000). The Karma of Brown Folk. Minnesota: University of Minnesota Press.

Puniyani, R. (2003). Communal politics: Facts versus myths. New Delhi: Sage Publications.

Puniyani, R. (1998). Secular challenge to communal politics: A reader. Mumbai: Vikas Adhyayan Kendra. 
Quddus, J. (2005). Hinduvta and Indian Diaspora. In R. Puniyani (Ed.), Religion, Power, and Violence: Expression of Politics in Contemporary Times (pp.144-156). New Delhi: Sage Publications.

Rai, V.N. (1999). Combating communal conflicts. Allahabad: Anamika Prakashan.

Sen, A. (2005). The Argumentative Indian: Writings on Indian History, Culture, and Identity. New York: Picador.

Sen, R. (2006). Us vs. them and Gandhi: The case of Hindu-Muslim conflict in India. Psychological Studies, 50(2\&3), 111-116.

Shankar, J., \& Gerstein, L.H. (2007). The Hindu-Muslim conflict: A pilot study of peacebuilding in Gujarat, India. Peace and Conflict: Journal of Peace Psychology, 13, 365-379. http://dx.doi.org/10.1080/10781910701471512

Stavenhagen, R. (1996). Ethnic conflicts and the nation-state. Macmillan Press LTD: London.

Stephan, W.G. \& Stephan, C.W. (2005). Intergroup relations program evaluation. In J.F. Dovidio, P. Glick \& L.A. Rudman (Eds.), On the nature of prejudice: 50 years after Allport (pp.431-446). Malden: Blackwell Publishing. http://dx.doi. org/10.1002/9780470773963.ch26

Strauss, A., \& Corbin, J. (1998). Basics of qualitative research: Techniques and procedures for developing grounded theory (2nd ed.). Thousand Oaks, CA: Sage Publications.

Swami, P. (2002a, March 16-29). Unquiet Peace. Frontline, 19(6). http://www.frontlineonnet.com/fl1906/19060210.htm

Tajfel, H., \& Turner, J. C. (1986). An integrative theory of social conflict. In S. Worchel $\&$ W. Austin (Eds.), Psychology of intergroup relations (pp. 7-24). Chicago: Nelson Hall.

Volkan, V.D. (2001). Transgenerational Transmissions and Chosen Traumas: An Aspect of Large-Group Identity. Group Analysis, 34(79), 79-97. http://dx.doi. org/10.1177/05333160122077730

Wilkinson, S.I. (2004). Votes and violence: electoral competition \& ethnic riots in India. Cambridge: Cambridge University Press. http://dx.doi.org/10.1017/ CBO9780511510458

Wilson, J.P. (2007). The lens of culture: Theoretical and conceptual perspectives in the assessment of psychological trauma and PTSD. In J.P. Wilson \& C.S. Tang (Eds.), Cross-cultural assessment of psychological trauma and PTSD (pp.3-30). New York: Springer. http://dx.doi.org/10.1007/978-0-387-70990-1_1

Wong, P.T. \& Wong, L.C.J. (Eds). (2006). Handbook of Multicultural Perspectives on Stress and Coping. New York: Springer. http://dx.doi.org/10.1007/b137168

Young-Bruehl, E. (1996). The Anatomy of Prejudices. Cambridge: Harvard University Press. 